\title{
A REVOLUÇÃO CUBANA E A FORMAÇÃO DO HOMEM NOVO (1959-1961)
}

\author{
Dayane de Freitas Colombo Rosa ${ }^{1}$, Roseli Gall do Amaral da Silva ${ }^{2}$, José Joaquim Pereira Melo ${ }^{3}$
}

${ }^{1}$ Mestranda do Programa de Pós-Graduação em Educação da Universidade Estadual de Maringá - UEM, Maringá, PR. Coordenadora pedagógica da Escola Municipal Alberto Bonini de Astorga e professora na Faculdade Astorga - Faast. E-mail: daymestrado@gmail.com

${ }^{2}$ Doutora em Educação pela Universidade Estadual de Maringá - UEM e Doutora em Estudos Clássicos (Mundo Antigo) pela Universidade de Coimbra/ UC. Docente da Universidade Tecnológica Federal do Paraná - UTFPR, Campus Apucarana-PR. E-mail: amararoseli@gmail.com

${ }^{3}$ Doutor em Historia e Sociedade pela Universidade Estadual Paulista - UNESP. Docente daUniversidade Estadual de Maringá - UEM, PR. E-mail: pereirameloneto@hotmail.com

\section{RESUMO}

Este trabalho tem como objetivo discutir a educação desenvolvida em Cuba, no período compreendido entre os anos de 1959-1961, cuja preocupação era a formação do homem novo, com vistas a consolidação do movimento revolucionário. O pressuposto teórico e metodológico implicou em analisar os processos educativos tendo como base sua concretude histórica, econômica e política, que visa atender aos interesses da sociedade em que se insere. A questão norteadora que suscitou a análise foi: quais os princípios culturais, morais e políticos que caracterizam o homem novo que se pretendeu formar em Cuba? Para tanto, utilizou-se como fonte o discurso de Ernesto Che Guevara "O socialismo e o homem em Cuba" (1995) e o discurso de Fidel Castro, no funeral do Che em 1997. Nos escritos de Che Guevara (1995), evidencia-se o manual de uma pedagogia revolucionária e, na exposição de Fidel Castro (1997) Che Guevara é apontado como o modelo de homem ideal, que atenderia as necessidades cubanas daquele período. A pesquisa justifica-se no atual contexto histórico educacional por fomentar a reflexão a cerca de uma pedagogia crítica e transformadora.

Palavras-chave: Cuba. Homem novo. Educação. Revolução.

\section{THE CUBAN REVOLUTION AND THE FORMATION OF THE NEW MAN (1959-1961)}

\begin{abstract}
This article aims to discuss the education development in Cuba during the years of 1959 to 1961, whose concern was the formation of the new man with the intention of consolidating the revolutionary movement.The theoretical and methodological assumption implied in analyzing the educational processes based on their historical, economic and political authenticity, which aims to attend to the interests of the society in which it is inserted.The guiding question that led to the analysis was: What are the cultural, moral and political principles that characterize the new man that was intended to be formed in Cuba? In order to do that, the speech made by Ernesto Che Guevara in the book "Socialism and Man in Cuba" (1995) and the speech made by Fidel Castro at Che Guevara's funeral in 1997, were used as source. In the writings made by Che Guevara (1995), the manual of a revolutionary pedagogy is evident and in the exposition portrayed by Fidel Castro (1997) Che Guevara is pointed as the model of an ideal man who would meet the needs of that period in Cuba. The research is justified in the current educational historical context by fomenting the reflection about a critical and transforming pedagogy.
\end{abstract}

Keywords: Cuba. New man. Education. Revolution.

\section{INTRODUÇÃO}

A história da educação em Cuba e o seu ideal formativo entre os anos de 1959 a 1961, não podem ser suficientemente compreendidos se não forem vistos como produtos de um percurso dotado de necessidades, preocupações e anseios cujas características dependem das bases materiais em que se estrutura a sociedade a que 
pertence. Sendo assim, o contexto de transição do modo de produção capitalista para o socialista em Cuba entre 1959 e 1961, de luta entre o velho e o novo, fez florescer a necessidade de formar o revolucionário homem novo, ou seja, a reestruturação produtiva que se iniciava exigia que a sociedade também fosse reestruturada, e os valores educativos precisavam dar suporte aos novos padrões de comportamento humano necessários para essa nova etapa do sistema de produção cubano.

Ernesto 'Che' Guevara em seu texto $O$ socialismo e o homem em Cuba dirigido a Carlos Quijano em 1965 explicita: "no nosso trabalho de educação revolucionária voltamos bastante sobre este tema educativo. Na atitude dos nossos combatentes visualizava-se o homem do futuro" (GUEVARA, 1965, p. 2-3). Para tanto, adotou-se como projeto antropológico a formação do homem novo, e valorizou-se a articulação entre educação, trabalho e cidadania em perspectiva politécnica a fim de proporcionar a ascensão dialética do senso comum à consciência filosófica, consciência coletiva e ou segundo Fidel Castro (1967), a consciência verdadeiramente comunista.

Diante dessas constatações, buscou-se responder a indagação: quais os princípios culturais, morais e políticos que caracterizam o homem novo apresentado como projeto antropológico da pedagogia revolucionária? O objetivo central foi refletir sobre o homem revolucionário, o homem novo que se pretendeu formar na pequena ilha a fim de consolidar a revolução e, quais as contribuições dessa formação para o atual contexto.

\section{METODOLOGIA}

O artigo foi estruturado por um caráter bibliográfico, dessa forma foi realizada uma leitura atenta e sistemática, do discurso de Ernesto Che Guevara "O socialismo e o homem em Cuba" (1965) e do discurso de Fidel Castro, no funeral do Che em 1967, assim como de fontes constituídas principalmente de livros e artigos de periódicos de autores comentadores como: Blanco e Dória (1982), Nepomuceno (1981), Huteau e Lautrey (1976) e Pérez (2001) que ajudaram a compreender o processo de transformação da sociedade que se pretendeu estudar, o contexto da reestruturação produtiva da mesma e as novas relações educativas necessárias para atender 0 novo modelo societário constituído.
A análise bibliográfica foi realizada a partir do pressuposto de que que "a educação se opera, na sua unidade dialética com a totalidade, como um processo que conjuga as aspirações e necessidades do homem no contexto objetivo de sua situação histórico-social" (CURY, 1986, p.13). Desse modo, a formação do homem novo em Cuba é construto humano e faz parte de uma totalidade denominada Revolução Cubana.

\section{RESULTADOS}

Depois de governo de ditadores como Gerardo Machado y Morales (1871-1939) e de Fulgencio Batista (1901-1973), desenvolveu-se em Cuba um cenário de marginalização e miséria de grande parte da população, precariedade da saúde e educação. A falta de legislação trabalhista permitia o pagamento por hora aos operários que, por conseguinte necessitavam fazer horas extras o que gerava a produção de um grande estoque em pouco tempo, fazendo com que os donos das indústrias de tabaco suspendessem a produção e também os salários dos operários. Segundo Eric Nepomuceno em sua obra "Cuba: Anotações sobre uma Revolução de 1981, em meados da década de 1950 nos grandes centros urbanos de Cuba:

\footnotetext{
"não havia praticamente nenhuma família que não tivesse alguma coisa que ver-promotores ou vítimas, espectadores ou cúmplices - com a corrupção, o tráfico de drogas, o jogo, o subemprego, a prostituição. Escapar da marginalidade era um milagre" (NEPOMUCENO, 1981, p.19).
}

Esse cenário fomentou o assalto ao quartel Moncada em 1953, movimento revolucionário contra a ditadura de Fulgêncio Batista denominado 26 de Julho. Mal sucedido, muitos dos participantes foram mortos e outros exilados. Os 82 homens que foram exilados retornam à Cuba em 1956, liderados por Fidel Castro, Che Guevara, Raul Castro e Camilo Cienfuegos, confrontam-se com as forças armadas do governo e sobreviveram apenas 22 deles que refugiam-se nas matas de "Sierra Maestra". Em 1959 após um longo período de luta armada, tem-se a ofensiva final e a tomada do poder pelos revolucionários.

Assim, a revolução cubana emanou do povo que estava insatisfeito com o governo de 
Batista e foi liderada por jovens universitários que a princípio não tinham conhecimento dos escritos de Marx e não se declaravam comunistas, apenas lutavam por justiça. Em 1961 Fidel Castro declara de forma explícita que a revolução cubana aderiu ao marxismo-leninismo e objetivava uma transformação social que não deveria acontecer apenas pela a luta armada, mas também pelo processo de formação da consciência. Cada cubano deveria ser um revolucionário, um formador e difusor de cultura, um professor, um mercador de sonhos livres da ignorância plena e argumentou que "revolucíon quiere decir destruccíon del privilegio, desaparición de la exploración, creación de una sociedad justa" (CUBA, 1961, p. 23).

Para a consolidação do processo revolucionário e o desenvolvimento dessa consciência fez-se necessário educar o povo, ao mesmo tempo em que as condições econômicas eram transformadas, pois os dirigentes da revolução entendiam que não é possível transformar o homem apenas pelos processos educativos. Porém, os processos educativos, foram pilares fundamentais para o desenvolvimento de uma consciência coletiva. Dessa forma, Che Guevara inspirado pelos escritos de Marx elaborou o manual da pedagogia revolucionária que visava formar o homem do futuro, o homem novo.

Para Che (GUEVERA, 1965), o homem novo, ou seja, o verdadeiro revolucionário deveria ser guiado "por grandes sentimentos de amor. É impossível pensar num revolucionário autêntico sem esta qualidade" (GUEVARA, 1965, p. 23). Che Guevara (1965) ainda ressalta que: "[...] todos os dias deve-se lutar para que este amor à humanidade viva e se transforme em fatos concretos, em atos que sirvam de exemplo, de mobilização" GUEVARA, 1965, p. 23).

Para que esse fim seja atingido, Che (1965) compreende que "a revolução se faz através do homem, mas o homem deve forjar dia a dia seu espírito revolucionário" (GUEVARA, 1965, p. 25). Para tanto, os processos educativos explicitados por meio da cultura e da arte devem acentuar ao homem que está sendo formado:

[...] sua participação coletiva consciente, individual e coletiva em todos os mecanismos de direção e produção, e ligá-la à idéia da necessidade da educação técnica e ideológica, de maneira que sinta como estes processos são estreitamente interligados e seus avanços paralelos. Deste modo alcançará a total consciência de seu ser social, o que equivale à sua plena realização como criatura humana, uma vez quebradas as correntes da alienação. (GUEVARA, 1965, p. 14).

Michel Huteau na obra intitulada "Cuba: revolução no ensino" do ano de 1976, explicita que o homem novo seria irmão gêmeo do que Marx denominava de homem integral ou omnilateral, pois "é a sua formação integral que Ihe permite ser consciente" (HUTEAU; LAUTREY, 1976, p. 197). Para os autores, a pedagogia revolucionária atua de forma mais expressiva na propagação dos princípios do trabalho produtivo e ou voluntário, formação ideológica e política, nas atividades culturais e na educação física.

Che Guevara (1965), explica em seu discurso "O socialismo e o homem" a nova condição que o trabalho deveria atingir por meio dos novos processos educativos:

A mercadoria homem cessa de existir e se instala um sistema, que outorga uma quota pelo cumprimento do dever social. Os meios de produção pertencem à sociedade e a máquina é apenas a trincheira onde o dever é cumprido. $\mathrm{O}$ homem começa a libertar seu pensamento da obrigação penosa que tinha de satisfazer suas necessidades animais através do trabaIho. Ele começa a se ver retratado em sua obra e a compreender sua magnitude humana através do objeto criado, do trabalho realizado. Isto já não significa deixar uma parte de seu ser em forma de força de trabalho vendida, que não lhe pertence mais, mas significa uma emanação de si mesmo, uma contribuição à vida comum, em que se reflete; 0 cumprimento do seu dever social. Fazemos todos o possível para dar ao tra- 
balho esta nova categoria de dever social e uni-lo, por um lado, ao desenvolvimento da técnica que dará condições para uma maior liberdade e, por outro lado, ao trabalho voluntário, embasado na concepção marxista de que o homem realmente alcança sua plena condição humana quando produz sem a compulsão da necessidade física de se vender como mercadoria (GUEVARA, 1965, p. 15).

As atividades artísticas e culturais seriam de grande relevância na pedagogia revolucionária, pois, na visão guevarista "falta o desenvolvimento de um mecanismo ideológico e cultural que permita a pesquisa e destrua a erva daninha tão facilmente multiplicável no terreno beneficiado pela subvenção estatal" (GUEVARA, 1965, p. 19). A erva daninha de que tratava o Che seria o imperialismo estadunidense. Para impedir que o povo cubano se pervertesse e, pervertesse também a nova geração a ser formada, era necessário para Che (GUEVARA, 1965), a formação de artistas autenticamente revolucionários para que ampliasse o campo da cultura revolucionária. Para os cubanos a arte é uma arma da revolução.

Corrobora-se com Huteau e Lautrey (1976), quando argumentam que a formação cultural e ideológica desempenha um papel fundamental na educação moral necessária para o desenvolvimento do modo de produção comunista. Para os autores, os cubanos "põem claramente uma cultura popular, assente no colectivismo, à cultura burguesa repassada de individualismo" (HUTEAU; LAUTREY, 1976, p. 210).

A educação física nesta pedagogia é entendida como fator contribuinte de uma formação moral, como meio de precaução para desenvolver a proteção do país em caso de invasão norte-americana e como manutenção das forças produtivas, da saúde do trabalhador voluntário. Podemos observar os princípios da pedagogia revolucionária na fala do comandante Che Guevara (1965), quando explicita a educação do homem novo:

Sua educação é cada vez mais completa e não esquecemos sua integração como o trabalho desde os primeiros momentos. Nos- sos bolsistas fazem trabaIho físico durante as férias ou simultaneamente com o estudo. O trabalho em certos casos é um prêmio, em outros um instrumento de educação, mas nunca um castigo. Uma nova geração nasce (GUEVARA, 1965, p. 21).

Como podemos observar os objetivos da educação revolucionária são de cunho ideológico - que também acontece em países nãorevolucionários, porém a diferença se encontra nos objetivos trilhados, a educação ideológica de Cuba pretende formar um homem que aprenda a ser, enquanto a educação ideológica dos países capitalistas pretende formar um homem que aprenda a ter. Para Huteau e Lautrey (1976), outro fator que diferencia o caráter ideológico dos processos educativos de Cuba e de outros países capitalistas é que não se encontra nesses países um dirigente declarando de forma explícita os objetivos educacionais de preparar a exploração do homem pelo homem, para os autores, "a grande força do sistema reside no facto de, para atingir estes objetivos, não ser necessário que eles sejam explícitos e que os educadores tenham deles consciência" (HUTEAU; LAUTREY, p. 200). Dessa forma, a diferença central da educação ideológica produzida em Cuba é que seus objetivos são explícitos e todo o povo deve tomar consciência deles e lutar para atingi-los, enquanto "em um país capitalista como a França, eles são atingidos de forma subreptícia, pelo próprio funcionamento da instituição escolar" (HUTEAU; LAUTREY, p. 201).

O homem novo ou homem revolucionário, o homem do século XXI, que para Che (1965), a sociedade cubana formaria deveria "ter consciência da necessidade de sua incorporação à sociedade e, ao mesmo tempo, de sua importância como motores da mesma" (GUEVARA, 1965, p. 11). Ou seja, o homem novo deveria assumir a responsabilidade de mestre e aprendiz, sendo essa a consciência revolucionária, aquela que parte do indivíduo para o coletivo, que resgataria a dignidade e criaria a identidade social revolucionária. Um homem que tem consciência, o que segundo Che Guevara significava o indivíduo que recebe continuamente o impacto do novo poder social e percebe que não pode estar completamente adequado a ele. $E$ que sob a influência da pressão que supõe a educação indireta, ele trata 
de construir seus próprios juízos de valor e se autoeduca. Um homem que possui o conhecimento da técnica e da ciência, que produz riqueza por meio da consciência coletiva e que ao mesmo tempo em que ensina também aprende.

O objetivo central da pedagogia revolucionária desenvolvida por Che era formar o homem novo e desenvolver o conhecimento científico e técnico do país, a fim de que o povo cubano pudesse atingir o máximo desenvolvimento das forças produtivas que segundo Marx seria o comunismo. Para Che Guevara (1965), o grau último do anseio revolucionário é ver o homem liberto da alienação.

\section{DISCUSSÃO}

Como discutido, o projeto antropológico da educação revolucionária em Cuba é a formação do homem novo que tem que lutar no plano material e moral contra o modo de produção vivenciado até então que primava pelo desenvolvimento de um homem individual e egoísta na sua essência. $O$ homem novo deveria ser aquele que antes mesmo da transformação do modo de produção comunista já possuía consciência comunista, ou seja, uma consciência coletiva, que apresente uma moral que proporcione o desenvolvimento ininterrupto da consciência.

Para que esse projeto futuro se concretizasse "era preciso dar ao povo cubano um modelo concreto e objetivo para o qual tende a revolução" (HUTEAU; LAUTREY, 1976, p. 199). Dessa forma, Che Guevara foi dado como modelo de homem novo ao povo cubano pelo comandante Fidel Castro em seu discurso pronunciado em la velada solemne em memoria do comandante Ernesto Che Guevara, em la plaza de la Revolucíon, em 18 de outubro de 1967. Fidel Castro (1967), explicita:

Si queremos expresar cómo aspiramos que sean nuestros combatientes revolucionarios, nuestros militantes, nuestros hombres, debemos decir sin vacilación de ninguna índole: iQue sean como el Che! Si queremos expresar cómo queremos que sean los hombres de las futuras generaciones, debemos decir: ¡Que sean como el Che! Si queremos decir cómo deseamos que se eduquen nuestros niños, debemos decir sin va- cilación: iQueremos que se eduquen en el espíritu del Che! Si queremos un modelo de hombre, un modelo de hombre que no pertenece a este tiempo, un modelo de hombre que pertenece al futuro, ide corazón digo que ese modelo sin una sola mancha en su conducta, sin una sola mancha en su actitud, sin una sola mancha en su actuación, ese modelo es el Che! Si queremos expresar cómo deseamos que sean nuestros hijos, debemos decir con todo el corazón de vehementes revoluciona-

rios: iQueremos que sean como el Che! (CASTRO, 1967, p. 7).

Além de expor sobre as características do bom guerrilheiro, como Fidel Castro (1967), em seu discurso salienta que não era apenas um bom combatente, ele era um homem de profunda consciência, de inteligência visionária, cultura e moral inquestionáveis. Para Fidel (CASTRO, 1967), Che era o modelo ideal de homem novo porque reunia em sua pessoa o homem de ação e o homem das ideias. Como revolucionário Che trazia as "las virtudes que pueden definirse como la más cabal expresión de las virtudes de un revolucionario: hombre íntegro a carta cabal, hombre de honradez suprema, de sinceridad absoluta, hombre de vida estoica y espartana" (CASTRO, 1967, p. 6).

Fidel Castro (1967), explica que Che seria o modelo vivo do projeto antropológico de Cuba, pois ele era um caso singular de homem raro que combinava em sua personalidade várias virtudes, as virtudes esperadas para o homem revolucionário, o homem emancipado, liberto da alienação e que se auto educa.

\section{CONCLUSÃO}

Pode-se considerar que a grande catarse do movimento revolucionário cubano foi fazer com que todo guerrilheiro fosse ao mesmo tempo mestre, conscientizando a população camponesa sobre as ideias revolucionárias e a necessidade da construção de uma nova moral e forma de trabalho produtivo e voluntário. 
A educação em Cuba além de ser um processo escolar ganhou características próprias de formação social, pois cada cubano deveria ser um propagador de cultura, e alguém que, além de se auto libertar, ser capaz de também propor ao outro libertação. Esses princípios deveriam vencer as fronteiras, pois o homem novo proposto em Cuba era um homem de guerra que assumia suas responsabilidades educacionais em uma proposta de cidadania solidária.

\section{REFERÊNCIAS}

BLANCO, A.; DÓRIA, C. A. Revolução Cubana: de José Martí a Fidel Castro (1868 - 1859). 2. ed. São Paulo: Brasiliense, 1982.

CASTRO, F. Discurso pronunciado por el comandante Fidel Castro Ruz, primer secretario del Comite central del partido comunista de cuba y primer ministro del gobierno revolucionario, en la velada solemne en memoria del comandante Ernesto Che Guevara, en la plaza de la Revolución, el 18 de octubre de 1967. 1967 Disponível in: <http://www.cuba.cu/gobierno/discursos/1967/ esp/f181067e.html>. Acesso em: 14 de novembro de 2017.

CUBA, Ministério de la Educación. Alfabeticemos manual para el Alfabetizador. La Habana: Imprenta Nacional, 1961.

CURY, C. R. J. Educação e contradição: elementos metodológicos para uma teoria crítica do fenômeno educativo. São Paulo: Cortez, 1986.

GUEVARA, E. C. O socialismo e o homem em Cuba. Montevideo: Semanário Marcha, 1965.

HUTEAU, M.; LAUTREY, J. Cuba: revolução no ensino. Trad. de Manuela Leandro e Fernanda Campos. Coimbra: Centelha, 1976.

NEPOMUCENO, E. Cuba: Anotações sobre uma Revolução. São Paulo: Alfa - Omega, 1981.

PÉREZ, M. M. Che Guevara: Contribuição ao pensamento revolucionário. São Paulo: Expressão Popular, 2001.

PEREIRA MELO, J. J.; AMARAL, R.G. A questão teoria e prática e suas implicações para a formação docente. In: CONGRESO INTERNACIONAL DE
SALUD MENTAL Y DERECHOS HUMANOS, 6, 2007, Buenos Aires. Trabajos 60 Congreso. Buenos Aires, 2007.

Submetido em: 15/08/2018

Correções Obrigatórias: 06/09/2018

Aceite Final em: 12/09/2018 